\title{
Resistivity Index (RI): A Fast and Reliable Indicator of Lupus Nephritis Severity
}

\author{
TAMER W. KASSEM, M.D.*; NADINE R. BARSOUM, M.D.* and \\ AHMED ABDEL SAMIE MAHMOUD, M.D.** \\ The Departments of Diagnostic \& Interventional Radiology, Faculty of Medicine, Cairo University* and \\ Radiology Department, Theodor Bilharz Research Institute**, Cairo, Egypt
}

\begin{abstract}
Background: Systemic lupus erythematosus (SLE) is an autoimmune disease characterized by production of pathogenic autoantibodies against nuclear structures. Lupus nephritis (LN) affects up to $60 \%$ of patients with SLE who develop immune complex-mediated renal injury and its squeal. Color Coded Doppler Ultrasound (CCDUS) allows non-invasive method for investigating renal hemodynamics. Renal resistive index (RI) measured using CCDUS reflects intrarenal vascular resistance. RI is an essential parameter in renal Doppler US and integrates arterial compliance, pulsatility and peripheral resistance.
\end{abstract}

Aim of Study: Evaluate the role of Color-Coded Doppler Ultrasound in the assessment of nephritis in SLE patients and correlation between resistivity index (RI) and lupus nephritis pathological classes. Such assessment will help reaching diagnosis, guide the choice of management and monitor the follow-up.

Patients and Methods: This study was conducted on ninety six SLE patients with renal affection, diagnosed clinically and laboratory first, then each patient included in the study was subjected to Ultrasound Doppler renal examination and renal biopsy. Twenty subjects with normal renal laboratory, ultrasound and Doppler findings were recruited as a control group. B-Mode ultrasound and Color-coded Doppler examination were performed using GE Logiq p5 Ultrasound machine by $(3.5-5 \mathrm{MHz})$ transducer. Doppler parameters were adjusted before Doppler examination scan. First general renal vascularity was checked then RI was calculated in different segments of intra renal arteries at upper, mild and lower poles. $\mathrm{RI}=$ (peak systolic velocity-end diastolic velocity)/peak systolic velocity. The normal value is $\approx 0.60$ with 0.70 being around the upper limits of normal. Finally, radiological findings were correlated with clinical findings and correlated with biopsy results.

Results: The study included 96 SLE patients, their ages ranged from (13-45) mean 28.19 \pm 8.026 . Males represented $12.5 \%$ (12 patients) and females represented $87.5 \%$ (84 patients). Renal biopsy showed 70 patients $(73 \%)$ with LN and 26 patients $(27 \%)$ with no renal affection.

Correspondence to: Dr. Tamer W. Kassem, The Department of Diagnostic \& Interventional Radiology, Faculty of Medicine, Cairo University, Egypt
The parenchymal echogenicity was increased in all LN seventy patients except one (1.5\%). 15 patients $(21.5 \%)$ scored grade I echogenicity while 16 patients $(22.9 \%)$ scored grade II and 38 patients $(54.1 \%)$ scored grade III.

There was a significant increase in renal RI in lupus nephritis LN patients, $p$-value 0.022 . Distribution of renal pathologic classes within the LN group. Class II (7 patients) represented $10 \%$, class III (27 patients) represented $38.5 \%$, class IV (22 patients) represented $31,5 \%$ and class, V (11 patients) represented $15.7 \%$ and class IV (3 patients) represented $4.3 \%$ of LN patients according to biopsy results. There was positive correlation between RI and renal biopsy classification with high significance, $p$-value 0.001 with $r=0.794$.

Conclusion: There is a significant correlation between pathologic RI and lupus nephritis histological classes suggesting a role for RI as a severity marker.

Key Words: Resistive index - lupus nephritis - kidney biopsy.

\section{Introduction}

SYSTEMIC lupus erythematosus (SLE) is an autoimmune disease characterized by production of pathogenic autoantibodies against nuclear structures [1]. Lupus nephritis (LN) affects up to 60\% of patients with SLE, either as the initial manifestation or during the course of the disease [2]. LN is an important predictor of poor outcome in patients with SLE. Renal affection may often remain unnoticed until nephritic syndrome or acute kidney injuries appear with increased risk of end-stage renal disease [3]

The term lupus nephritis encompasses diverse patterns of renal disease encountered in SLE, including glomerular, tubulo-interstitial and vascular pathology. Particularly, the term lupus nephritis should be reserved for immune complexmediated renal injury and its squeal [4].

Greater knowledge of SLE pathogenic mechanisms improved survival of patients with earlier 
diagnosis and better therapeutic approaches. However, LN still means a poorer outcome and lower survival rate [5-7]; therefore, identifying new markers of LN severity and outcome is an unmet need.

Color Coded Doppler Ultrasound (CCDUS) allows non-invasive method for investigating renal hemodynamics. Renal resistive index (RI) measured using CCDUS reflects intrarenal vascular resistance [8].

$\mathrm{RI}$ is an essential parameter in renal Doppler US and integrates arterial compliance, pulsatility and peripheral resistance [9].

The aim of this study was to analyze the association between the renal arterial resistivity index (RI) and the histological features of lupus nephritis (LN).

\section{Aim of study:}

The study objective was to evaluate the role of Color-Coded Doppler Ultrasound in the assessment of nephritis in SLE patients and correlation between resistivity index (RI) and lupus nephritis pathological classes. Such assessment will help reaching diagnosis, guide the choice of management and monitor the follow-up.

\section{Patients and Methods}

\section{Patients:}

This is a prospective study included Ninety six patients (12 males and 84 females) diagnosed with SLE according to 2019 European League Against Rheumatism/American College of Rheumatology Classification Criteria for Systemic Lupus Erythematosus [10] having suspected renal affection were recruited, their ages ranged between (13-45) years with mean age $28.19 \pm 8.026$, Twenty subjects with normal renal laboratory, ultrasound and Doppler findings were recruited as a control group.

Patients and control group were referred from Rheumatology department to Radiology Department, Cairo University from January 2019 to July 2019. to:

\section{Each patient included in the study was subjected}

- History taking.

- Clinical examination.

- Labs: Urine proteins 24h analysis, Creatinine blood level and Urea blood level.

- Ultrasound Doppler renal examination.

- Renal biopsy.
All participants were informed about the idea of the study and signed a written consent. The study was approved by the local ethical committee of the institute.

Inclusion criteria were SLE with suspected clinical renal affection.

Exclusion criteria included renal artery stenosis, heart failure, hepatic diseases and urinary tract obstruction to exclude the presence of other pathology that could affect RI of intra renal arteries.

Clinical and laboratory evaluation included serum creatinine $(\mathrm{mg} / \mathrm{dL})$ levels, blood urea nitrogen $(\mathrm{BUN}, \mathrm{mg} / \mathrm{dL})$ levels and daily urinary protein excretion $(\mathrm{g} / 24 \mathrm{~h})$ were measured at the time of the assessment.

All patients were subjected to history taking, US exam for both kidneys, color coded Doppler ultrasound CCDUS examination for intra renal arteries on both sides, renal biopsy and histopathological evaluation for lupus nephritis pathological classification.

\section{Methods:}

\section{Equipment:}

B-Mode ultrasound and Color-coded Doppler examination were performed using (GE Logiq P5 Ultrasound machine) using (3-5 MHz) transducer.

\section{Technique:}

The patients were scanned in supine and lateral decubitis positions, placing the probe in the right lower intercostal space in the mid axillary line. For the right kidney, the liver was used as "acoustic window" with the probe is slightly directed posteriorly (toward the kidney). Rocking the probe gently (up and down or side to side) to scan the entire kidney.

The upper pole of the kidney, particularly on the left side, sometimes is hidden behind rib shadows. This fact makes it very important for us to use breathing techniques by asking the patient to inspire or exhale, which allows for subtle movement of the kidney and multiple windows to visualize the entire kidney and obtaining longitudinal (long axis), and transverse (short axis) views.

B-mode findings were recorded accurately including renal size, cortical thickness and renal echogenicity. The echogenicity of the kidney tissue was determined in contrast to the liver and spleen and was graded as follows:

- Grade 1: Same echogenicity as normal liver or spleen. 
- Grade 2: More echogenic than liver or spleen but still with cortico-medullary differentiation.

- Grade 3: The kidney as a whole is brighter (cortex and medulla) with loss of differentiation. The presence of back pressure changes was reported.

Before Doppler Examination scanning we should check the followings:

CCDUS findings included measurement of RI at three different segmental intra renal arteries near the junction between renal sinus and parenchyma at each pole and middle zone.

Our radiological findings were correlated with clinical findings and compared to biopsy results. Classification of biopsy findings was made according to International Society of Nephrology/Renal Pathology Society (ISN/RPS) classification of lupus nephritis (2003) [11]. The kidney biopsy allows an assignment to the five different classes of lupus nephritis LN according to the 2003 International Society of Nephrology (ISN)/Renal Pathology Society (RPS) classification.

- Class I : Minimal mesangial affection.

- Class II : Mesangial proliferative.

- Class III: Focal Proliferative.

- Class IV: Diffuse proliferative.

- Class V : Membranous.

- Class VI: Advanced sclerosing.

\section{Data analysis and interpretation:}

Data were statistically described in terms of mean \pm standard deviation $( \pm \mathrm{SD})$, median/range, or frequencies and percentages. Chi square $(\chi)$ test was performed for comparing categorical data. Exact test was used instead when the expected frequency is less than 5 . The correlation between different variables was done using Pearson moment correlation equation for linear relation in normally distributed variables and Spearman rank correlation equation for non-normal variables/non-linear monotonic relation. $p$-values less than 0.05 was considered statistically significant. All statistical analysis was obtained using computer program SPSS (Statistical Package for the Social Science; SPSS Inc., Chicago, IL, USA) release 15 for Microsoft Windows (2006).

\section{Results}

This study included 96 SLE patients, (12 males and 84 females) their ages ranged between (13$45)$ years with mean age $28.19 \pm 8.026,70$ SLE patients showed lupus nephritis while 26 SLE showed no evidence of lupus nephritis by renal biopsy and the mean duration of LN was $50.91 \pm$ 39.983 months. Twenty subjects with normal renal laboratory, ultrasound and Doppler findings were recruited as a control group.

There was a significant increase in renal RI in LN patients when compared with non renal SLE patients and normal group ( $p$-value 0.022) (Fig. 1) $\&$ (Table 1).

The parenchymal echogenicity was increased in all LN seventy patients except one (1.5\%). 15 patients $(21.5 \%)$ scored grade I echogenicity while 16 patients (22.9\%) scored grade II (Fig. 2) and 38 patients (54.1\%) scored grade III (Figs. 3-5). All non renal SLE patients and normal controls had normal echogenicity. The grade of echogenicity correlated with the severity of the disease. Renal biopsy results according to ISN/RPS classification of LN was as follows: Class II represented $10 \%$ of $\mathrm{LN}$ patients $(\mathrm{n}=7)$, class III represented $38.5 \%$ $(\mathrm{n}=27)$ (Fig. 2), class IV represented $31.5 \%(\mathrm{n}=22)$ (Fig. 3), class V represented $15.7 \%(\mathrm{n}=11)$ (Fig. 4) and class VI represented $4.3 \%(n=3)$ (Fig. 5) of LN cases.

There is positive correlation between RI and renal biopsy classification with high significance ( $p$-value 0.001 with $r=0.794$ ) (Fig. 6).

Table (1): Descriptive statistics of average serum creatinine, PSV and renal RI with standard deviation in LN patients, non renal SLE patients and control group.

\begin{tabular}{cclll}
\hline & $\begin{array}{c}\text { LN } \\
\text { group }\end{array}$ & $\begin{array}{c}\text { Non renal } \\
\text { SLE group }\end{array}$ & $\begin{array}{c}\text { Normal } \\
\text { group }\end{array}$ & $p$-value \\
\hline Serum creatinine & 2.056 & 0.920 & 0.820 & $p=0.228$ \\
$(\mathrm{mg} / \mathrm{dl})$ & \pm 2.0950 & \pm 0.1304 & \pm 0.1095 & \\
PSV $(\mathrm{cm} / \mathrm{sec})$ & 106.00 & 101.00 & 106.00 & $p=0.522$ \\
& \pm 9.857 & \pm 5.477 & \pm 5.477 & \\
Renal RI & 0.6634 & 0.5820 & 0.5820 & $p=0.022$ \\
& \pm 0.08627 & \pm 0.01483 & \pm 0.01643 & \\
\hline
\end{tabular}

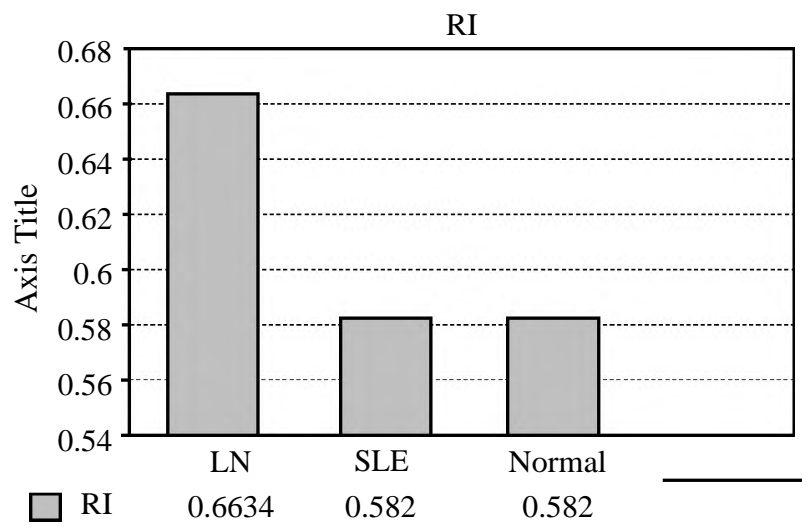

Fig. (1): The significant increase in RI between groups. 



Fig. (2): Female SLE patient 17 years old diagnosed 4 years ago. (A and B) CCDUS findings: Normal perfusion of the kidney, normal RI=0.55 and 0.61. (C) B-Mode: Normal site, size and shape of kidney with no back pressure changes. Increased parenchymal echogenicity with impaired differentiation (grade II nephropathy). Renal biopsy: Class III LN with acute and chronic lesions.
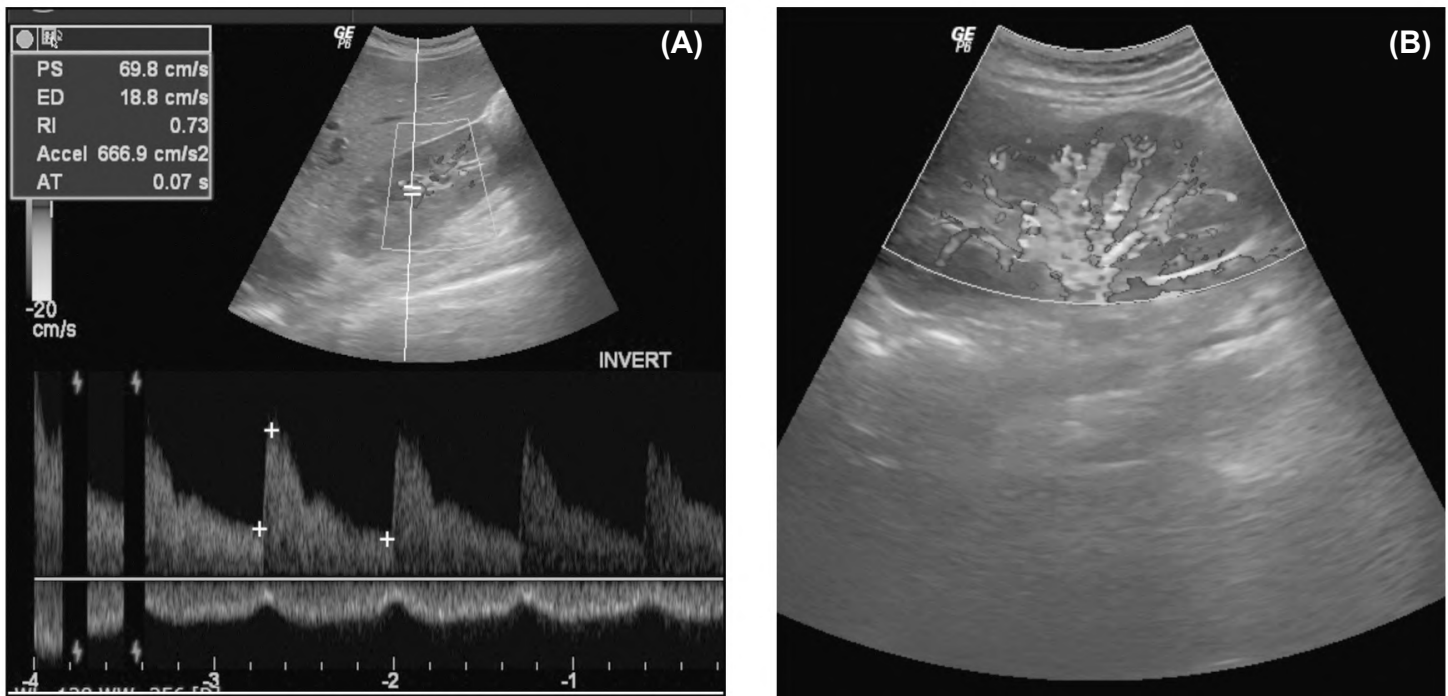

Fig. (3): Female SLE patient 35 years old diagnosed 5 years ago. (A and B) CCDUS findings: Normal perfusion of the kidney, increased RI=0.73. B-Mode: Normal site, size and shape of kidney with no back pressure changes. Increased parenchymal echogenicity with impaired differentiation (grade III nephropathy). Renal biopsy: Class IV LN with acute and chronic lesions. 

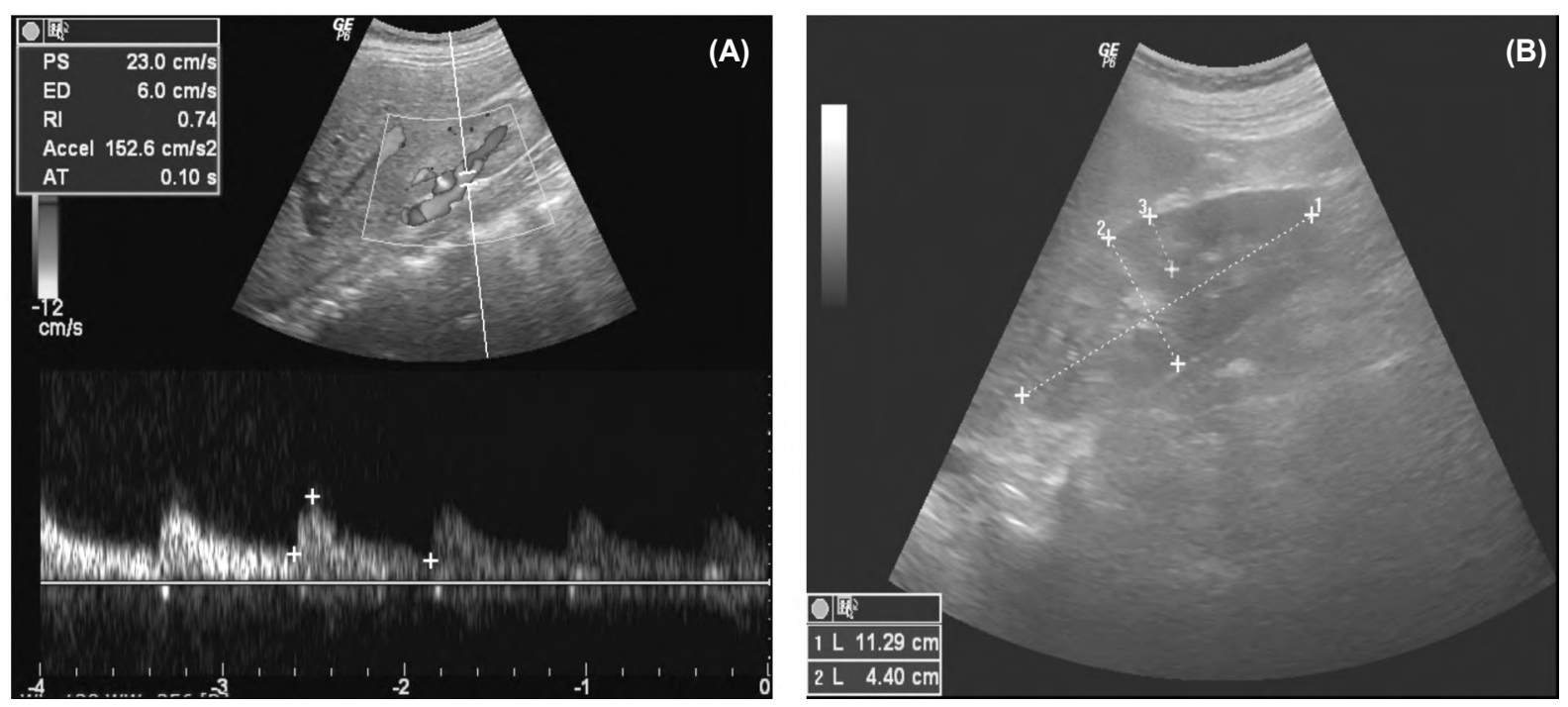

Fig. (4): Female SLE patient 13 years old diagnosed 3 years ago. (A and B) CCDUS findings: Normal perfusion of the kidney, increased RI=0.74. (C) B-Mode: Normal site, size and shape of kidney with no back pressure changes. Increased parenchymal echogenicity with lost differentiation (grade III nephropathy). Renal biopsy: Class V LN with acute and chronic lesions.
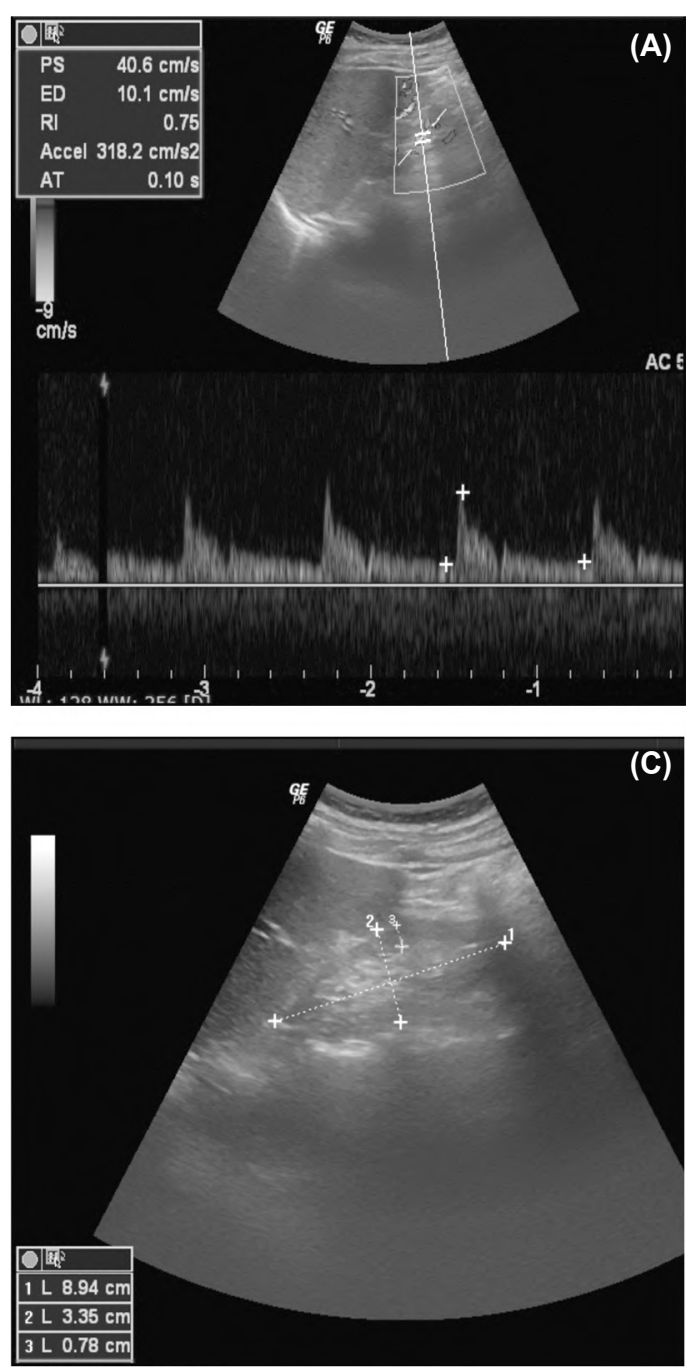

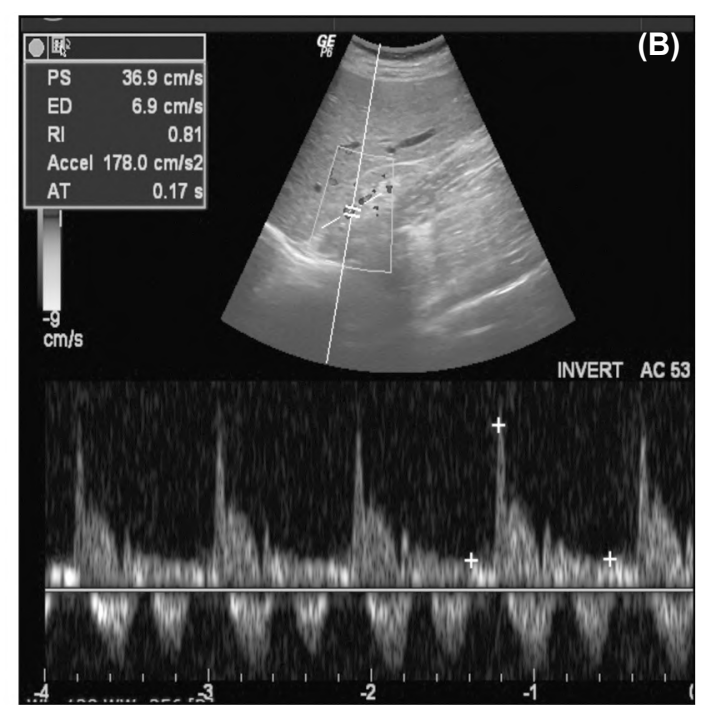

Fig. (5): Female SLE patient 28 years old diagnosed 10 years ago. (A and B) CCDUS findings: Normal perfusion of the kidney, increased $\mathrm{RI}=0.75$ and 0.81 . (C) B-Mode: bilateral relatively small sized kidneys with no back pressure changes. Increased parenchymal echogenicity with lost differentiation (grade III nephropathy). Renal biopsy: Class VI LN with acute and chronic lesions. 
RI

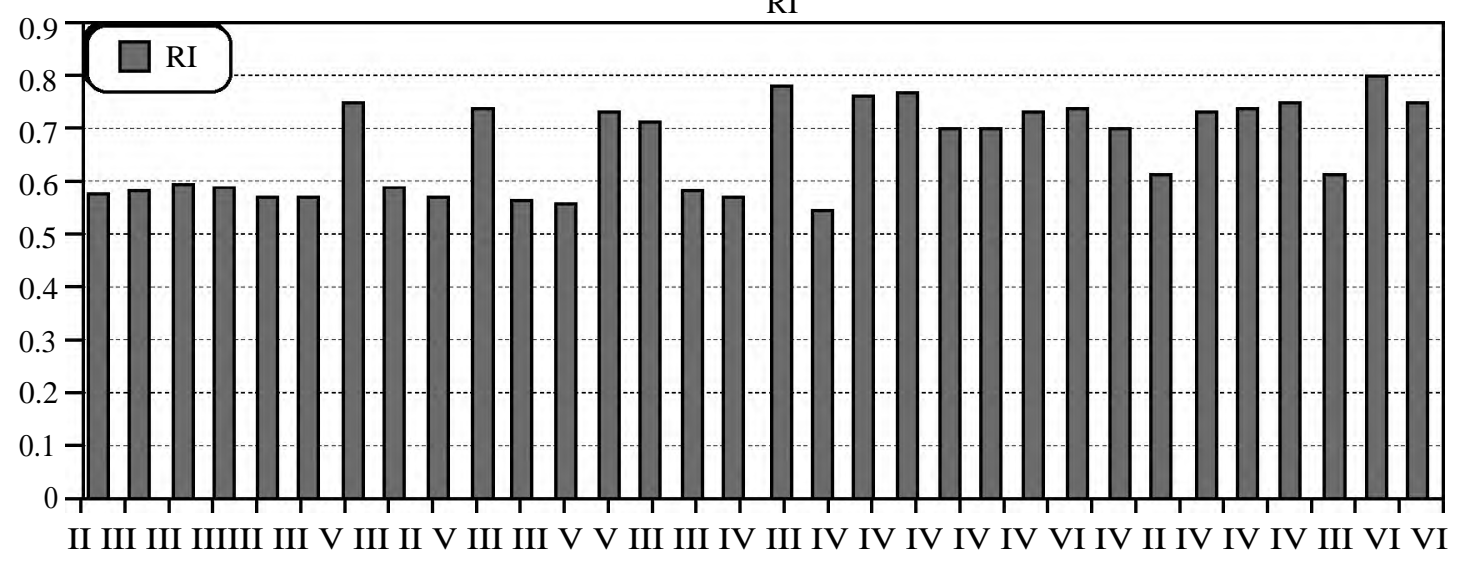

Fig. (6): Positive correlation between biopsy classification and RI.

\section{Discussion}

SLE is defined clinically and involves multiple organ systems. It is associated with antibodies directed against cell nuclei. It is a multisystem affection especially skin, kidney and joints $[12,13]$

LN affects up to $60 \%$ of patients with SLE, either as the initial manifestation or during the course of the disease [2] . LN is an important predictor of poor outcome in patients with SLE. Renal injury may often remain undiagnosed until nephritic syndrome or acute kidney injuries appear with increased risk of end-stage renal disease [3] .

Glomerular disease usually develops within the first few years of SLE onset. A biopsy studies demonstrate some degree of renal involvement in almost all patients [13]. Renal manifestations range from asymptomatic hematuria or proteinuria to overt nephrotic syndrome, uremia and renal failure [14].

Assessing histopathologic categorization, fibrosis, activity and chronicity is of great importance in planning a rational treatment strategy for the patient [3]. The kidney biopsy can accurately determine the five different classes of lupus nephritis LN according to ISN/RPS classification [11].

Bleeding diathesis, solitary kidney, uncontrolled severe high blood pressure and uncooperative patient considered as absolute contraindications for renal biopsy. Relative contraindications for renal biopsy are uraemia, skin infection at the biopsy site, urinary tract infection, pregnancy, medications that interfere with clotting (warfarin or heparin) and obesity $[\mathbf{1 5 , 1 6 ] ~}$.

The most common complication of kidney biopsy is bleeding. Bleeding complications include perinephric hematoma, macroscopic haematuria or bleeding from larger blood vessels that lie adjacent the kidney. Blood clots in the bladder may obstruct the bladder and lead to urinary retention. Less commonly, the bleeding may cause shock or anemia [16]. Bandari et al., [15] recorded rates of bleeding complication after percutaneous renal biopsy ranging from $0.3 \%$ to $7.4 \%$.

Renal US is still the first step in evaluation of kidneys in many pathologic conditions including renal failure, urinary abnormalities and arterial hypertension [17]. It is commonly used in clinical practice, is simple and non invasive. However, its accuracy depends on the skill of performer and body fat mass in patients [18].

Doppler waveforms of renal arterial blood flow have been investigated to determine pathologic and physiologic conditions. One of the parameters introduced is renal resistive index (RI), which is considered a reflection of renal parenchymal resistance, has been widely used to support diagnostic and therapeutic procedures $[8,9]$.

There is no general agreement about the meaning and the predictive value of renal RI in patients with LN. Few studies investigated the application of Doppler sonography in evaluation of intra renal hemodynamic abnormalities in LN have been published so far [17].

The RI integrates peripheral resistance and pulsatility giving an essential parameter in renal Doppler US [9]. An increase in the RI value has been described in chronic kidney diseases such as acute rejection of renal transplant, renal vein thrombosis and urinary tract obstruction as well as after administration of drugs such as angiotensinconverting enzyme inhibitor $[2,19,20]$. 
Previous studies based on non homogenous populations (diabetes, IgA nephropathy, renal amyloidosis, $\mathrm{LN}$ ) reported a significant association between the RI and tubulo-interstitial and vascular lesions, but there are no data clearly correlating this index with glomerular lesions $[\mathbf{1 9 , 2 1 , 2 2 ]}$.

To the best of our knowledge, only few previous studies evaluated the possible role of the RI in LN patients. Conti et al., [17] described RI of 0.7 in $29 \%$ of $34 \mathrm{LN}$ patients. They described a correlation between a pathologic RI and many factors including presence of interstitial disease, creatinine level and histologic chronicity index. Pathologic RI and chronicity index were related to poorer renal outcome after one year follow-up.

In this study, the mean age of the patients was $28.19 \pm 8.026$ years and the mean duration of $\mathrm{LN}$ was $50.91 \pm 39.983$ months. The current study found a significant increase in the renal RI in LN patients with advanced classes especially class IV compared to age matched healthy patients $p=0.001$, with high significance as $r=0.7$. These findings were in accordance to study performed by Conti et al., [17] who found that the RI has been advocated as a marker of LN.

Significant correlation of pathologic RI with glomerular lesions was explored in current work as RI more than 0.7 was recorded in a larger percentage of class IV, V, VI LN cases compared to other classes $(p$-value $=0.001)$. More recently, Gao et al., [23] retrospectively reviewed $42 \mathrm{LN}$ patients and observed a significantly higher RI in patients with moderate than in those with mild renal cortical fibrosis. However, the authors focused their attention only on fibrotic score, not differentiating between different histologic classes.

In the present work, 26 non renal SLE patients and 20 healthy persons were encountered as control groups. Pathologic RIs were identified only in $\mathrm{LN}$ patients with $p$-value 0.022 matching with Conti et al., who found pathologic RIs only in $\mathrm{LN}$ patients suggesting a link between the renal involvement and RI modification.

Class IV is recognized as the most severe, rapidly declining in kidney failure $[\mathbf{5 , 2 4}]$. The most interesting result of the present work is the association of increasing RI with class IV LN compared to the other classes. Pathologic RI was identified almost exclusively in LN patients in this histologic class, suggesting the potential use of RI as a severity marker. These results were consistent with previous reports $[\mathbf{2 , 9 , 2 0 , 2 2 ]}$.
This was noted by an earlier study done by Chen et al., [19] as RI demonstrated a correlation with a number of histological parameters and the most evident was observed with renal fibrosis especially renal tubule interstitial fibrosis.

Significant association of RI with severe renal lesions as in class IV (diffuse lesion) was reported in the current study in accordance with Bigé et al., [25] who stated that there is a significant correlation between RI and severity of renal affection.

\section{Conclusion:}

Renal RI was found to increase positively correlating with $\mathrm{LN}$ classification. Thus, CCDUS can be useful in prediction of LN class. Despite the small number of the patient population, the study was able to predict that CCDUS plays an important role in diagnosis of different LN classes and RI could be used as a fast and reliable marker for LN severity.

CCDUS examination and RI calculation is highly recommend for LN patients with absolute or relative contraindications for renal biopsy. Combination of CCDUS and clinical data could be of great help for those patients, as RI could predict nephritis class affecting the outcome and treatment plan.

\section{Conflict of Interests:}

The authors declare no conflict of interests.

\section{References}

1- PALEY M.A., STRAND V. and KIM A.H. J.: From mechanism to therapies in systemic lupus erythematosus. Current Opinion in Rheumatology, 29 (2): 178-186, 2017.

2- MORREALE M., MULÈ G., FERRANTE A., et al.: Association of Renal Resistive Index with Markers of Extrarenal Vascular Changes in Patients with Systemic Lupus Erythematosus Ultrasound in Medicine \& Biology, 42 (5): 1103-1110, 2016

3- HEINLEN L.and CHAKRAVARTY E.F.: LUPUS NEPHRITIS: Duration of Therapy and Possibility of Withdrawal Adv Chronic Kidney Dis., 26 (5): 387-392, 2019.

4- KIREMITCI S. and ARZU E.: "Classifying lupus nephritis: An ongoing story". The Scientific World Journal, 580620. doi: 10.1155/2014/580620, 2014.

5- BERTSIAS G., TEKTONIDOU M., AMOURA Z., et al.: Joint European League Against Rheumatism and European Renal. Association-European Dialysis and Transplant Association. (EULAR/ ERA-EDTA) recommendations for the management of adult and pediatric lupus nephritis. Ann. Rheum. Dis., 71 (11): 1771-82, 2012.

6- RAIMBOURG Q. and DAUGAS É.: [Lupus nephritis]. Nephrol. Ther., 15 (3):174-189, 2019. 
7- CONTI F., CECCARELLI F., MASSARO L., et al.: Biological therapies in rheumatic diseases. Clin. Ter., 164 (5): 413-428, 2013.

8- GAREEBALLAH A., GAMERADDIN M., SALIH S. and TAMBOUL J.: Sonographic assessment of kidneys and associated abdominal findings in patients with renal parenchymal diseases Int. J. Res. Med. Sci., 5 (3): 1048$1052,2017$.

9- MELEK E., BASKIN E, GULLEROGLU K., et al.: The predictive value of resistive index obtained by Doppler ultrasonography early after renal transplantation on longterm allograft function. Pediatr Transplant. Mar., 21 (2), 2017.

10- ARINGER M., COSTENBADER K., DAIKH D., et al.: European League Against Rheumatism/American College of Rheumatology Classification Criteria for Systemic Lupus Erythematosus. Arthritis \& Rheumatology, 71 (9): 1400-1412, 2019.

11- WILHELMUS S., ALPERS C.E., COOK H.T., et al.: The Revisited Classification of GN in SLE at 10 Years: Time to Re-Evaluate Histopathologic Lesions. J. Am. Soc. Nephrol., 26 (12): 2938-46, 2015.

12-RIVAS-LARRAURI F. and YAMAZAKI NAKASHIMADA M .A.: Systemic lupus erythematosus: Is it one disease? Reumatol. Clin., 12 (5): 274-81, 2016.

13- FERNÁNDEZ DE LARRINOA R.: What is new in systemic lupus erythematosus Reumatol. Clin., 11 (1): 27 32, 2015.

14- SHARIATI-SARABI Z., RANJBAR A., MONZAVI S., et al.: Analysis of clinicopathologic correlations in Iranian patients with lupus nephritis, Rheum. Dis., 16 (6): 731 8, 2013.

15- BANDARI J., FULLER T.W., et al.: Renal biopsy for medical renal disease: Indications and contraindications. Can. J. Urol., 23 (1): 8121-6, 2016.

16- LUCIANO R.L. and MOECKEL G.W.: Update on the
Native Kidney Biopsy: Core Curriculum. American Journal of Kidney Diseases, 73 (3): 404-415, 2019.

17- CONTI F., CECCARELLI F., GIGANTE A., et al.: Ultrasonographic evaluation of renal resistivity index in patients with lupus nephritis: Correlation with histologic findings. Ultrasound Med. Biol., 40 (11): 2573-80, 2014.

18- LI X., XU X., ZHANG Q., et al.: Diffusion weighted imaging and blood oxygen level-dependent MR imaging of kidneys in patients with lupus nephritis. Transl. Med., 24; 12 (1): 295, 2014.

19- CHEN Q., HE F., FENG X., et al.: Correlation of Doppler parameters with renal pathology: A study of 992 patients. Exp. Ther. Med.,7 (2): 439-442, 2014.

20- NAESENS M., HEYLEN L., LERUT E., et al.: Intrarenal resistive index after renal transplantation. N. Engl. J. Med., 369: 1797-1806, 2013.

21- HANAMURA K., TOJO A., KINUGASA S., et al.: The resistive index is a marker of renal function, pathology, prognosis, and responsiveness to steroid therapy in chronic kidney disease patients. Int. J. Nephrol., 139565, 2012.

22- SUGIURA T. and WADA A.: Resistive index predicts renal prognosis in chronic kidney disease: Results of a 4-y follow-up. Clin. Exp. Nephrol., 15: 114-120, 2011.

23- GAO J., CHEVALIER J., AUH Y., et al.: Correlation between Doppler parameters and renal cortical fibrosis in lupus nephritis: A preliminary observation. Ultrasound Med. Biol., 39: 275-282, 2013.

24- PETRI M., ORBAI A., ALARCON G., et al.: Derivation and validation of the Systemic Lupus International Collaborating Clinics classification criteria for systemic lupus erythematosus. Arthritis Rheum., 64: 2677-2686, 2012.

25- BIGÉ N., LÉVY P. and CALLARD P.: Renal arterial resistivity index is associated with severe histological changes and poor renal outcome during kidney disease. BMC. Nephrol., 13: 139, 2012. 


\section{مؤشر مقاومة RI مؤشر سريع وموثوق للأكتشاف المبكر

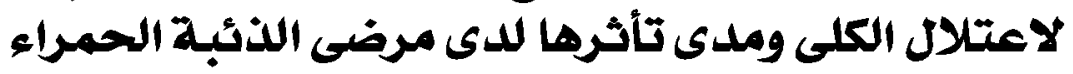

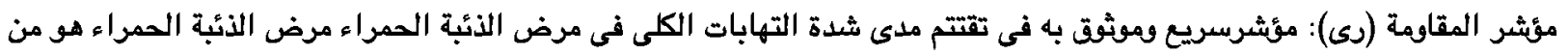

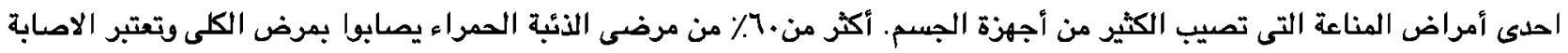

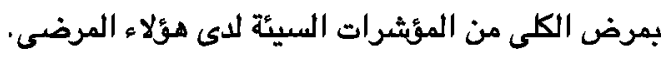

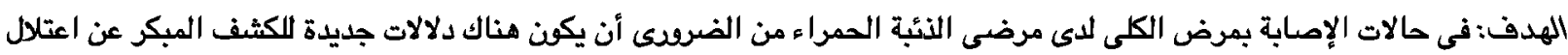

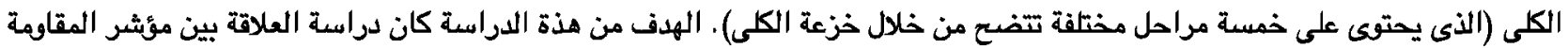
لاى شرايين الكلى باستخدام الدوبلر ونتائج خزعة الكلى.

المرضى والطرق: وقد قمنا بـراسة سته وتسعون مريضا مشكوك باصابتهم بمرض الكلى لمرضى النتبّة الحمراء (اربعة وثمانين من الاناث

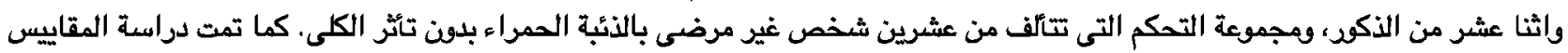


النتائج: الزيادة فى متوسط مئشر المقاومة لاى شرايين الكلى فى مرضى الذئبة الحمراء المصابين بمرض الكلى ترتبط بشكل إيجابى

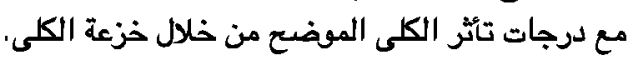
الاستتاج: قياس معامل متوسط مؤشر المقاومة لدى شرايين الكلى يمكن آن يستخدم كمؤشر للاكتشاف المبكر عن أعتلال الكلى ومدى تائرما لاى مرضى الذئبة الحمراء. 